\title{
Moral Stance and Agency in Schooling Narratives
}

Mariana Souto-Manning

The University of South Carolina - Columbia, SC

\begin{abstract}
Neste trabalho emprego análise de narrativas conversacionais para mostrar como recursos lingüísticos são usados com a finalidade de expressar agência e posição moral nas narrativas de duas mulheres. Analiso a progressão de narrativas de abandono à escola a narrativas de primeiros dias de volta à escola, no processo de negociação de narrativas de retorno à escola. Resultados desse estudo indicam mudanças nas narrativas dessas mulheres. Inicialmente, elas retratavam-se como vítimas, devido a situações criadas por outras pessoas (narrativas de abandono à escola). Posteriormente, passaram a se colocar como agentes de mudança. Episódios analisados foram selecionados de entrevistas de história de vida conduzidas em julho de 2003.

In this paper I employ conversational narrative analysis to show how linguistic resources are used to convey agency and moral stance in two women's narratives. I analyze how they progress from dropping-out narratives to first-days narratives while negotiating returning-to-school narratives. Results indicate that these women's narratives changed from portraying themselves as helpless victims in which they did not orient to goodness due to someone else's action (dropping-out narratives) to perceiving themselves as active, ergative agents. The episodes analyzed were selected from life history interviews conducted in July, 2003.
\end{abstract}

\section{Introduction}

Stories can be told in a multiplicity of ways. In the same way that there are different ways to report or retell an event determined by factors such as teller, listener, and context, there are also many ways to analyze narratives, and therefore, many definitions of narrative. In this paper I analyze how two women narrate their experiences and perceptions of dropping-out of school as children and consequently returning to an alternative educational program as adults. More specifically, I analyze how linguistic resources are used to convey moral stance (OCHS; CAPPS, 2001) and agency in these women's narratives. The episodes 
analyzed were selected from ethnographic life history interviews conducted in July, 2003.

\section{Narrative}

There are multiple definitions of the term narrative in qualitative research. For example, Polkinghorne (1995) writes about narratives as texts thematically organized in terms of temporal units and plots. "Narrative is the type of discourse composition that draws together different events, happenings, and actions of human lives into thematically unified goal-directed processes" (POLKINGHORNE, 1995, p. 5). Ochs and Capps (2001) define narrative as co-constructed in conversations. Accordingly, there are two kinds of narrative inquiry corresponding to paradigmatic cognition and narrative cognition (BRUNER, 1985; POLKINGHORNE, 1995). These two kinds of cognition influence two kinds of narrative analysis: analysis of narratives (paradigmatic cognition - analyzing common elements and concepts in narratives) and narrative analysis (narrative cognition - telling emplotted stories; anecdotal description of specific incidents).

In this study, I employ the analysis of narratives framework, progressing from stories to common elements. From here on I refer to what Polkinghorne (1995) calls analysis of narrative, moving from stories to common elements, by the more frequently used term narrative analysis. While Labov's model (LABOV, 1973; 1982) provides a familiar reference to an analytical method based on the structure of narrative data, here I center on the model proposed by Ochs and Capps (2001), which analyzes the dimensions of conversational narrative tellings.

Ochs and Capps (2001) posit that conversational narratives orient to five dimensions: (1) Tellership, or who is telling the story; (2) Tellability, or how interesting the story is; (3) Embeddedness, or how the narrative is situated within other stretches of text or talk; (4) Linearity, the sequential and/or temporal ordering of events; and (5) Moral Stance, the moral values being conveyed through the telling. All narratives vary in degree along continua within each of these dimensions. One or all of these dimensions may be analyzed in a narrative. Here, I focus on moral stance, and how they negotiate the telling of their schooling stories orienting to a certain set of morals. 
Narratives function as a way of ordering and making sense of experiences (OCHS; CAPPS, 2001). In making sense of lived experiences, narrators negotiate the tension between two human impulses. On one side of this tension, they seek out narrative as a way to provide some order for our experiences, to our sense of the puzzling and chaotic unfolding of our lives. On the other side, they resist paring down our stories to fit in neatly ordered narrative sequences, to cater solely to our listeners' (or society's) expectations and morals. While the women participants in this study make sense of their experiences, they do so in a neatly organized way - structurally - while orienting to societal and/or community morals.

In addition to the dimensions and tensions present in narratives, the narratives in this study illustrate the presence of narrative components which facilitate the understanding of the logic of events (OCHS; CAPPS, 2001). These are the major building blocks tellers use in composing storylines. They include: setting, unexpected event, psychological/physiological response, object state change (change in the state of an entity in the physical world), unplanned action (unintended behavior or a behavior that is not directed by a goal), attempt (behavior directed at solving a problematic or unexpected event) and consequence (repercussion of psychological or physiological response). In developing logics for present and future, the linearity of a narrative establishes a coherent framework for interpreting past and future experiences, as "the past provides a blueprint for the time to come" (OCHS; CAPPS, 2001, p. 192). Ochs and Capps (2001) illustrate further that not everything is clearly told in narratives. Some things are beyond the face value of the narrative. What is left untold is grounded in morality, as teller works to produce a coherent story based on a moral frame.

Moral agency (or the moral dimension of a narrative) is constructed through life narratives and through the agent positioning and use of linguistic devices. Tellers use narrative to order their experiences and make sense of their lives and their orientation to moral good. Their moral universe is context dependent, and agency is crafted within the context of narration (RYMES, 1995). This construction of self and agency is understood through discursive and grammatical analysis. Agency is then cast as self-defense or a necessity in the use of narration as a moral 
framework. As you will see in this study, agency is first portrayed in alignment with broader societal patriarchal morals, and later by acting according to group negotiated ethics. In their returning to school narratives, Joice and Nataly portray themselves as good as defined within the culture circle communities. In the circles, "social roles, social identity and moral agency are reconstituted collaboratively through narrative and in turn construct narrative" (RYMES, 1995, p. 497). As you will see, these women's narratives are constructed and co-constructed according to Bruner's narrative logic (BRUNER, 1991), making the listener feel sympathetic to their positioning.

The complexity of goodness is defined by: (1) good as sociallyconceived moral sources, (2) the concept of understanding goodness as recognizing, loving, respecting and being able to live up to them, and (3) words as a moral force, as able to empower in the form of an effective articulation, for instance. In making sense of our lives through narratives, we strive to make sense of our lives in terms of goodness (what is socially defined as good) and normalcy (what adheres to society's expectations).

These women's dropping out narratives are reconstructed reports of what happened casting the agents (themselves) in terms of good and normal, in terms of actions that would have been taken by you or me (RYMES, 1995). This is the dimension I propose to analyze in two narratives - those of Joice and Nataly. The analysis of the episodes focuses primarily on who is the active agent in the narrative and the moral stance dimension of the narratives.

\section{Research Design \& Methods}

As Joice and Nataly told their schooling histories in an informal interview setting, their schooling narratives formed in a very clear conversational narrative. When talking about their lives, in ethnographic life history interviews, Nataly and Joice clearly articulated self-contained conversational narratives that conveyed their schooling history. I look at how they display themselves morally and agentically in droppingout of school as children and in returning to school as adults.

These narrative episodes emerged as clear-boundary conversational narratives, and were constructed in a very similar fashion. They are 
important because they can potentially add to the understanding of how dropping-out of school and returning to school episodes are conveyed by protagonists through narratives, and the linguistic role tellers embody in terms of agency and moral stance.

In this article, I analyze their narrative constructions in terms of moral stance and in terms of agents or subjects in their narratives. I specifically look at how these two low socio-economic status women negotiate moral stance and agency as their schooling narratives progress from dropping-out of school to returning to school, as they become part of Freirean culture circles (FREIRE, 1959).

After identifying the conversational schooling narratives co-told by myself and each of the participants in this study, I labeled the different narrative components to see how two dropping-out narratives - two first-days-of-school narratives and two returning-to-school narratives compared across these two interviews. Components are as presented in Ochs and Capps (2001). Moral stance is determined in terms of linguistic positioning of narrator in the story and elicitation of feelings of empathy. Some limitations of this interpretation might be due to double translation issues (BEHAR, 2003), considering the fact that I translated their responses from oral to written format as well as from Portuguese into English.

\section{Participants}

Joice and Nataly are pseudonyms for two women living below the poverty line in the rural area of the Northeastern Brazilian state of Pernambuco. These women have many things in common. Both of them dropped out of school as children, went to a large urban center to work as domestic employees, and later returned to their birth city. At the time the data for this study was collected, they were both in culture circles, a Freirean democratic pedagogy program that seeks to teach participants to read and write words while reading and re-writing the world (FREIRE, 1959; 2000).

Joice was the single mother of two elementary school boys. She dropped out of school after second grade, and didn't return until 2003, when she was 24 years old. She lived in the Brazilian city of Bezerros in a simple but very clean house with her two sons. She participated in the city's Freirean culture circles in the evenings. 
Nataly is the proud mother of an adoptive daughter. A 34-year-old woman, she lived with her husband and daughter in Bezerros, Northeastern Brazil. She participated in a different culture circle than the one Joice did, but both were in the city of Bezerros. She dropped out of school after third grade. Her husband also dropped out of school as a child, and she looks forward to the time in which he can join her in the culture circle. Even though children are welcome, the culture circle she attended took place at their daughter's bedtime.

In talking about their lives, both Joice and Nataly narrated their stories of dropping-out of school and how they negotiated their re-entry as adults. Their narratives are analyzed in the following sections.

\section{Dropping-out Narratives}

In telling their dropping-out stories, both Joice's and Nataly's narratives portray themselves in terms of moral goodness. They both dropped out of school as children, but neither of them constructed a dropping-out narrative in which they portrayed themselves as agents of that change. Their stories place the agency with some other character. They construct their narratives in a way that a listener or reader cannot help but understand their situations, and empathize with them. Joice portrays herself as good, as not challenging the societal rule that women didn't ride horses, which resulted in her dropping-out of school. Could she have ridden horses to school if she had insisted? Could she have done it without her parents' knowledge? These actions would therefore position her as not being good and she chose to orient herself to goodness. Based merely on the analysis of this interview, I cannot report whether that is what actually happened. I can report, though, that in this dropping-out narrative, she constructs her storyline so as to position herself as a good person, a person with constant and certain moral stance (OCHS; CAPPS, 2001, p. 20). In the present time, she again orients to goodness and portrays herself as an ergative agent (which can be verified by her use of $I \mathrm{am}$ ).

In constructing her dropping-out narrative, Nataly portrays herself as a victim of other people's actions and decisions. 
Nataly: I was one time in second grade. I liked going to school. My father and my mother let me go, but then when I was held back it was different. I didn't want to go back to school. That was not a good year for me. All my friends were in third grade. My mother said girls helped at home. It was better to learn how to take care of the house than to go to school. The last year I went to school my teacher gave me bad grades and... then my father said I should stop going to school. He said to help my mother. She needed help. Then I didn't go anymore.

She does not cast herself as responsible for dropping-out and could do nothing to prevent it since she was held back, she was given bad grades, and her father advised her to drop out because her mother needed help. She orients herself to goodness - she only mentions in passing her lack of interest in going back to school as a result of retention. Who wouldn't lose interest when given bad grades and held back to repeat the same grade? Who would challenge a father's plea to help the mother? The narrator in this case uses narrative to locate herself as a good person, whose actions aligned with the definition of moral goodness.

In a shorter narrative, Joice constructs her dropping-out narrative in terms of her orientation to goodness.

Joice: I went to school u]ntil the third grade, and then I wasn't given an opportunity to study anymore. My parents moved to a farm to work there... and there was no school there. My brothers could ride the horse to the city to go to school, but my father didn't let me. I asked to go. My father said that women wore skirts and didn't ride horses and he said that women who went away from home without their father and mother became badly spoken of. So I couldn't go. I wanted to go but I couldn't. Until now. Now I am here to continue.

Education is portrayed as an opportunity that was taken away from her. Her parents moving to a farm placed her geographically far from a school. The only way to go to school was to ride a horse. Therefore, riding a horse, in her narrative/perception, would be contrary to the morals in her community, as she reports her father saying (intertextually). Who would want to be a girl badly spoken of? She portrays herself as wanting to go to school, but not being able to. In narratives, past and present 
may web together (OCHS; CAPPS, 2001). Joice concludes her narrative with the present in which she takes an ergative agent role (DURANTI, 1997) in being responsible for her return to school.

While these are not necessarily the attitudes listeners would have taken, one cannot but agree with their orientation to goodness as they are portrayed in the women's narratives. Not only the content of the stories, but also the way the narratives are told, indicate the moral stance of the narrator. These women, then, make sense of their own lives in terms of the moral good. To recall, "social roles, social identity and moral agency are reconstituted collaboratively through narrative and in turn construct narrative" (RYMES, 1995, p. 497). Therefore, it is important to remember the role of narrative in making sense of or stabilizing chaotic lives.

To summarize, Nataly's and Joice's narratives are similar in terms of structure, which indicates their orientation to rules. They both start with a setting (in terms of grade level), which is propelled by the questions I asked. Then, an unexpected event follows in both narratives followed by a psychological/physical response and an object state change. They both set up their narratives in very similar manners. There are some differences in terms of structure, but there are many more similarities. Probably, being from the same geographical area, both Joice and Nataly are familiar with the preferred way to present a highly tellable tale (one of narrative's dimensions according to OCHS; CAPPS, 2001), similarly securing the attention of the listener. Both narratives have high tellability with one active teller (as an entire episode is narrated before I speak again). They are organized in a linear manner-both temporal and causal. They have some characteristics of stand alone episodes, detached and not embedded (although not purely). The narratives Joice and Nataly tell as each of them converses with me fit neatly ordered sentences, being compatible with their orientation of what is morallyand socially-acceptable. As mentioned previously, they are both certain and constant in terms of moral stance. The most canonical (and necessarily hypothetical) narrative artifact we can imagine would be: 1) told by a single author; 2) highly tellable (exciting); 3) minimally embedded (as a stand-alone storybook on the shelf); 4) highly linear; and 5) explicit in its moral stance (the moral of the story is $\mathrm{x}$ ). Both of these narratives orient to this ideal narrative artifact even though the 
literacy level of these women is quite limited, which shows the highly elevated complexity of talk.

We could conflate the fact that Nataly and Joice show themselves as victims in the dropping-out narratives exactly because they were children and more dependent on adults, but both grammatically and in terms of framing, their narratives align with morals, be it larger community patriarchal morals (at first) or collective morals developed within a group context (as in the Culture Circles). This analysis is also supported by previous studies, as according to Rymes (2001), high school students positioned themselves clearly as victims in their dropping-out of school stories. Therefore, we see that both as young children and high school students, individuals who dropped-out tend to align with what is morally defined as good within a community (TAYLOR, 1992).

\section{First-days Narratives}

In telling the stories of their first days as they returned to school, both Nataly and Joice narrate feelings of reluctance, shame, or fear that they would not fit in and orient to moral stances. Their narratives are therefore more uncertain in terms of moral stance (OCHS; CAPPS, 2001) than their dropping-out narratives.

In her narrative, Joice portrays herself initially as unsure, feeling childish, afraid and ashamed.

Joice: I don't know... I felt like... so childish... with fear. You know, to go to school after so many years. I didn't know what I was going to see. I felt like I shouldn't be in school...because I thought that I should have learned to read and write when I was young. I felt ashamed and with fear.

She indicates by the use of these words, her feelings of inappropriateness upon returning to school. In addition to portraying herself as inappropriate, Joice's story brings attention to the timing of her educational experience. The expression "after so many years" conveys her presence at school after the right time, reflecting a fluid, uncertain moral stance (OCHS; CAPPS, 2001). In attempting to secure high tellability, Joice uses "you know" in her narrative and achieves both the purpose of engaging the listener and indicating a commonly known 
unwritten rule (context) that adulthood is late to go to school. As she relates that she shouldn't be in school, she should have learned how to read and write when younger, Joice portrays society's expectations and the uncertain moral stance in her narrative. Even though Joice portrays herself as unsure and possibly inappropriate, she positions herself in the ergative agentic position (DURANTI, 1997), indicated by the use of the pronoun I plus an active verb.

On the other hand, Nataly provides a mixture of agency in her narrative - at times she is in the agentic position, and at times others are, portraying a feeling of unsureness. She portrays herself as ergative agent at times, but they takes the ergative agent role a couple of times. She reports feeling ashamed of how other people would see her. $I$ didn't know what other people were going to say. She portrays herself as being afraid that she won't be seen as "good" or as orienting to a moral stance as she held dispreferred labels, such as single mother, illiterate, and trash dump worker. Her feelings of inappropriateness are replaced by the portrayal of agency exerted by they. She ends by portraying that even her sons wanted to attend daily (which implies she did too, by her use of even). Her repetition that she has no husband may indicate the importance of having a husband to orient to moral stance in her context.

In terms of structure, the two narratives are very similar.

Nataly: A little ashamed. I didn't know what other people were going to say. A mother who doesn't know how to read nor write, with two sons, no husband, working at the dump, no husband. I didn't know what people would think. But they didn't judge me. They supported me and helped me solve my problems. They made me feel well. Now I know that even my sons want to come every day.

Initially, I provide the setting when I ask about how each of them felt during the first day in the adult education program they attend. Following the question with a psychological/physiological response, both of them narrated an unexpected event. After the unexpected event, Joice portrays the continuation of her psychological/physiological response displayed between the setting I provided and the unexpected event. After that, both narratives align again in terms of components (OCHS; CAPPS, 2001), and feature an attempt and a consequence. In 
terms of tellership, the two narratives have two co-tellers, as I provide the setting and therefore engage in the construction of narrative with both Joice and Nataly. We need to consider that the similarity in structure might have been determined by the common teller, i.e. myself in asking the questions. The result, nevertheless, is a less preferred possibility of tellability than that portrayed by the dropping-out narratives analyzed earlier in this paper. While not dichotomous, these first-days narratives align with multiple co-tellers as opposed to the dropping-out of school narratives in which each had one active co-teller.

\section{Returning-to-school Narratives}

Joice's return-to-school narratives are marked by the heavy use of ergative agency (DURANTI, 1997), indicating agency being enacted by the narrator. Joice's first narrative is shaped by the setting suggested by my question. This illustrates the co-construction of narrative (OCHS; CAPPS, 2001). This also indicates my tendency to linearity in the construction of narrative as I provide settings temporally organized (indicated by the question and now?, following the question in which I ask her to address the first day of school). Therefore, as interviewer, I take an active role in the enactment of the linearity of Joice's narratives by the questions I ask. It is not possible to determine by analyzing the data presented above, whether or not Joice's narrative would have been constructed so linearly had I not offered such a "possibility" (OCHS; CAPPS, 2001, p. 20).

Joice: $\quad$ Now I like to come. I like to talk with my group. Even when I have problems at home...we solve them together. One day....Maria said... she was very sad because ....she was selling sandwiches that she made but she was losing money. We helped her to solve this. She learned how to sell the sandwiches ... and started earning money. That's what we learn. Real stuff. It is not like, this letter is A. We learn that the letter is A...but the teacher doesn't make us feel dumb. I want to come every night. I only missed class once when I was sick. I felt so sad. It's a group of friends, really. A group of people who don't judge me. I know they understand me and help me grow and learn. 
In this narrative, Joice portrays herself as protagonist in her story, helping others and solving problems together with others - orienting to goodness (TAYLOR, 1992) and moral stance (OCHS; CAPPS, 2001; RYMES, 1995). She portrays herself as an ergative agent indicated by the use of the pronoun I plus active verb, and the pronoun we plus active verb. The teacher as authority figure and active agent is used merely as an example in negation. This is illustrated in "but the teacher doesn't make us feel dumb". Joice uses intertextuality (FAIRCLOUGH, 2003) in the underlined text to illustrate someone else's story as the "attempt" (OCHS; CAPPS, 2001, p.173) of her primary narrative - solving each other's problems in the group. She refrains, though, from telling her own story, orienting to goodness and helping others with their problems. Furthermore, Joice portrays herself as having an affective (fond) tie to the circles or to the group and this is one of the reasons she gives for returning day after day. She mentions that she only missed class once - differently from before, when she dropped out - when she was sick (morally oriented explanation). She portrays a desire to come to class (good) over feeling sad when she misses classes (bad). Even when portraying the actions of others as helping her, she positions herself as an ergative agent (DURANTI, 1997).

Nataly's narrative is shaped by the setting provided by my question. This illustrates the co-construction of narrative (OCHS; CAPPS, 2001). In her narrative, she progresses from "I didn't know things" to social action, when she tells the teacher she needs to be a "good teacher" and teach her children with appropriate methods. She portrays the collaborative nature of this program by mentioning "here everybody helps everybody, people help each other all the time, everybody is learning together, and even the teacher learns with us". Her use of "everybody" as agents helping other and learning together (as ergative agents) conveys her perception of the collaborative nature of this program. By mentioning that "even the teacher learns with us," she portrays, by the use of even, that this is not a normal situation, but an exception. She makes use of intertextual narrative (underlined) to illustrate how members of the group ("a woman") get help from others, yet not exposing herself as needing help and continuing to display a certain and constant moral stance. This way, she constructs herself as oriented to doing good and helping others. She then identifies herself as enjoying helping her children, but not being the teacher. 
One of the very reasons she entered the program was now being seen more critically; she constructs herself questioning what a good mother is (which does not include being a teacher), and becoming more agentic as she challenges the teacher to become a good teacher. As part of this learning community, and belonging to it as indicated above, Nataly orients herself to the morals of that community and invites the teacher to do so as well.

Nataly: When I didn't know things. But here everybody helps everybody. People help each other all the time. It is not like in school. Who is best? Everybody is learning together. Even the teacher learns with us. We decide the important things for us to work. It is good. People talk, help each other and learn. Just now, there was a woman who didn't know something, then another woman was helping her...with helping her son with his homework. I like helping with homework, but I am not their teacher. The teacher said I needed to be a good mother. I went there another day... and said that I was trying to be a good mother, going to school and all. Now she needed to try to be a good teacher. I told her how we learned in this program and how my boys do well. I told her that if she got them studying things that they do everyday they might do better at school. Now I know it doesn't depend on me or on them only. It depends on the teacher. They know a lot. The teacher needs to use what they know to teach them better. Now I want to see if she is going to try to be a good teacher like I am trying to be a good mother.

While Nataly portrays herself as agent in attempting to change her children's situation at school, she does so by talking to the teacher, making suggestions and inviting her to be a good teacher, and not by teaching her children in lieu of the teacher, as she says she is not a teacher. The responsibility for the success of her children is then defined by her in her narrative as a joint effort between the teacher, the children, and herself.

In both narratives, the women portray themselves as having social agency and even (as portrayed in the second narrative) social action. It appears from the narratives of these two women that upon their return to an educational environment, there is a sense of agency conveyed in their narratives and indicated by their use of the pronoun I plus an 
active verb. But, is this a result of the particular program per se, or simply a result of them being back in school? At this point and with the data at hand this is unknown. It may be speculated from their narratives that the collaborative aspect was important in their development of agency as narratives go from uncertainty to group agency to individual agency, but not affirmed. Also, the absence of judgment from members of the group might have contributed to their agentic development.

In terms of structure, their narratives are similar, as both feature narratives within a narrative. This indicates an orientation to a certain set of rules, and mirrors the process to which they orient to contextuallysituated morals. They both use intertextuality to illustrate their points and as a result produce a less linear narrative. Joice's three episodes illustrated in the first narrative are embedded and provide narratives that fall on the dispreferred end of the continuum (OCHS; CAPPS, 2001, p. 20) of possibilities for most dimensions. Both of them represent agentic roles in their narratives and orientation to goodness (TAYLOR, 1992).

\section{Discussion and Implications}

Overall, the narratives of these women changed from portraying themselves as helpless victims in which they did not orient to goodness due to someone else's action (dropping-out narratives) to perceiving themselves as active, ergative agents and telling stories of themselves promoting change in their immediate environment (returning-to-school narratives). Their perceptions of the change in their oppressive conditions were reflected by, as well as enacted in, the construction of their narratives. The implication of this study is that narratives may be constructed in such a way that narrators are responsible for their actions, so that they see themselves as able to take action and change the conditions in which they exist (RYMES, 2001).

I found from analyzing this data and by comparing dropping-out narratives with the returning-to-school narratives of Nataly and Joice that their narratives orient to moral goodness (TAYLOR, 1992). While the former is true, the first days of school narratives do not present the preferred moral stance dimension variation (OCHS; CAPPS, 2001); however, the dropping-out and returning-to-school narratives orient themselves to the preferred end of the moral stance dimension continuum. 
Ergative agent positioning changes happened in a temporal progression when dropping-out narratives were compared to returningto-school narratives. There was no ergative agency enacted by the narrators in dropping-out narratives, there was somewhat of a mixture of agency in the first-days narratives and there was a strong sense of agency enacted by the language and continuing narrative constructions employed by both Joice and Nataly.

As indicated by Rymes (1995), dropping-out narratives can be oriented to moral stance and goodness in a particular context. In the context of her study, stabbing a person was constructed in narrative by the author as a noble action, something anyone in his situation would do. In the context of this study, taking into consideration the unsaid societal rules (FOUCAULT, 1978), these women constructed narratives that portrayed themselves as displaying a constant moral stance by adapting to the societal expectations in their dropping-out narratives. In the dropping-in narratives presented by Rymes in her book Conversational Borderlands (2001), "authors focus on their role as a returning student and distance themselves from their previous role as disengaged students" (RYMES, 2001, p. 73). As in Rymes's book, Nataly and Joice construct themselves as different from their roles in the dropping-out narratives, as distancing themselves from that narrative.

Ultimately, this study contributes to the understanding of the development of one's role as ergative agent in returning-to-school narratives (or dropping-in narratives). After constructing a narrative that situates the narrator, who dropped out of school as the victim of other people's actions and having a certain moral stance, narrators construct an unstable narrative marked by shame and confusion - portrayed by the first-days narratives of Joice and Nataly. In these narratives, the narrators (Joice and Nataly) place themselves as agents but do not orient to goodness or do not fully enact the role of ergative agent. This kind of narrative construction can be the intermediary step in between the construction of dropping-out of school narratives and returning-toschool narratives and may facilitate those who have constructed dropping-out of school narratives to transition toward the desired and morally certain return to school narrative. 


\section{References}

BEHAR, R. Translated woman: Crossing the border with Esperanza's story. Tenth Anniversary Edition. Boston: Beacon Press, 2003. 392p.

BRUNER, J. The narrative construction of reality. Critical Inquiry, v. 18, p. 1-21, 1991.

BRUNER, J. Vygotsky: a historical and conceptual pespective. In: WERTSCH, J. W. (Ed.). Culture, communication and cognition: Vygotskian perspectives. Cambridge: Cambridge, 1985. p. 21-34.

DURANTI, A. Meaning in linguistic forms. In: DURANTI, A. (Ed.). Linguistic anthropology. Cambridge: Cambridge University Press, 1997. p.162-213.

FAIRCLOUGH, N. Analysing discourse: textual analysis for social research. London; New York: Routledge, 2003. 272 p.

FOUCAULT, M. The history of sexuality: an introduction. New York: Vintage Books. 1978. 176 p.

FREIRE, P. Educação e atualidade brasileira. 1959. Unpublished doctoral dissertation. Universidade de Recife, Recife, Brazil.

FREIRE, P. Pedagogy of the oppressed. New York: Continuum, 2000. 192 p.

LABOV, W. Language in the Inner City: Studies in the Black English Vernacular. Philadelphia: University of Pennsylvania Press, 1973.

LABOV, W. Speech actions and reactions in personal narratives. In: TANNEN, D. (Ed.). Analyzing discourse: Text and talk. Washington, DC: Georgetown University Press, 1982. 400p.

OCHS, E.; CAPPS, L. Living Narrative: Creating Lives in Everyday Storytelling. Cambridge: Harvard University Press, 2001. 368 p.

POLKINGHORNE, D. Narrative configuration in qualitative analysis. International Journal of Qualitative Studies in Education, v. 8, n. 1, p. 5-23, 1995.

RYMES, B. Conversational borderlands: Language and identity in an alternative urban high school. New York: Teachers' College Press, 2001. 193 p. RYMES, B. The construction of moral agency in the narratives of high-school drop-outs. Discourse and Society, v. 6, n. 4, p. 495-516, 1995.

TAYLOR, C. Sources of the self: the making of the modern identity. Cambridge, MA: Harvard University Press, 1992. 620 p. 